\title{
Fischer-Tropsch synthesis using bio-syngas and $\mathrm{CO}_{2}$
}

\author{
S. Srinivas, Ranjan K. Malik, and Sanjay M. Mahajani \\ Department of Chemical Engineering, Indian Institute of Technology Bombay, Powai, Mumbai-400 076, India
}

\begin{abstract}
While Fischer-Tropsch synthesis (FTS) using coal and natural gas in conventional reactors is an almost well-established technology, the production of liquid hydrocarbons from syngas obtained from biomass is in its preliminary stages of commercialization in countries like Germany. With concerns about global warming and ways of disposing of $\mathrm{CO}_{2}$ being searched for, $\mathrm{CO}_{2}$ hydrogenation using FTS to liquid hydrocarbons can act as a $\mathrm{CO}_{2}$ sink. A brief review of FTS using $\mathrm{CO}_{2}$-rich syngas is given in this paper, looking at FTS as a technology that can help reduce global warming and as a process integration alternative. The reverse water gas shift ( $r$-WGS) reaction is vital for $\mathrm{CO}_{2}$ hydrogenation. We have studied the effect of this using an FT kinetic model and have proposed a new flow sheet alternative for FTS using $\mathrm{CO}_{2}$-rich syngas. Simulations suggested that this new process gives better conversion of $\mathrm{CO}_{2}$. The product selectivity and yields from an FT plant are vital to make the process viable economically.
\end{abstract}

\section{Introduction}

Fischer-Tropsch synthesis (FTS) is one of the technology alternatives being used by SASOL, South Africa, for the past five decades to obtain liquid fuels from synthesis gas or syngas [Dry, 2002]. The synthesis gas feed can come from coal or residual oil gasification, methane reforming, or from biological wastes. Syngas obtained from biomass is termed "bio-syngas" and FTS using this is under development. With concerns about global warming and ways of disposing of $\mathrm{CO}_{2}$ being searched for, $\mathrm{CO}_{2}$ hydrogenation using FTS to liquid hydrocarbons can act as a $\mathrm{CO}_{2}$ sink. This is more useful if $\mathrm{H}_{2}$ can be produced without considerable $\mathrm{CO}_{2}$ emissions, using hydel, solar or nuclear power [Riedel et al., 1999]. The conventional methods of syngas production (steam reforming of natural gas or coal gasification) also release good amounts of $\mathrm{CO}_{2}$, which is separated before the syngas is fed to FT reactors. In the following sections, a review of the $\mathrm{CO}_{2}$ hydrogenation studies reported in the literature is presented. Since the WGS and r-WGS reactions play an important role in maintaining the $\mathrm{H}_{2}$ balance and $\mathrm{CO}_{2}$ conversion, a study of r-WGS was carried out and the results are discussed.

In a novel approach, Gouse et al. [1993] present integrations of photovoltaic (PV) cells and integrated coal gasification combined cycle (IGCC) technologies to reduce carbon dioxide emissions. In one of these alternatives (Figure 1), liquid transportation fuels are produced by using the carbon dioxide emissions from the IGCC plant with hydrogen produced from PV electrolysis of water in an FT process. Thus, FTS for $\mathrm{CO}_{2}$ hydrogenation can be viewed as a technology that can help reduce global warming and as a process integration alternative. FTS can be seen as a process helping to maintain a closed carbon cycle - carbon from emissions of $\mathrm{CO}_{2}$ from transportation fuels is fixed back in them utilizing $\mathrm{H}_{2}$, which may be obtained from solar power, etc. The same principle may be applied for bio-syngas. Apart from $\mathrm{CO}_{2}$ emission mitigation, $\mathrm{CO}_{2}$ hydrogenation would help in bringing down the cost of the FT process. The FT process, be it from coal or biomass, involves a clean-up process where $\mathrm{NH}_{3}$, $\mathrm{H}_{2} \mathrm{~S}$ and $\mathrm{CO}_{2}$ are removed from the syngas before it is sent to the FT reactors. On the other hand, if $\mathrm{CO}_{2}$ is hydrogenated in the FT reactor by means of a suitable catalyst, $\mathrm{CO}_{2}$ removal from raw syngas is not needed. This would reduce to some extent the cost involved in the $\mathrm{CO}_{2}$ separation step alone, while $\mathrm{NH}_{3}$ and $\mathrm{H}_{2} \mathrm{~S}$ still need to be removed from the raw syngas.

\section{2. $\mathrm{CO}_{2}$ hydrogenation}

\subsection{Syngas from coal gasification}

Rao et al. [1992] report that some gasifiers for coal gasification like the conventional Lurgi process give a $\mathrm{CO}_{2}$ rich syngas (17\% $\mathrm{CO}, 38 \% \mathrm{H}_{2}, 32 \% \mathrm{CO}_{2}$, rest others). Iron catalysts used in the conventional FT reactors exhibit WGS activity as well. WGS activity helps the reactors to handle $\mathrm{CO}$-rich gas deficient in $\mathrm{H}_{2}$ by generating hydrogen. On the other hand, for a $\mathrm{CO}_{2}$-rich syngas, sufficient $\mathrm{H}_{2}$ is necessary to first enable the reverse-WGS reaction to form $\mathrm{CO}$, which then takes part in the FT polymerisation reactions. This is the mechanism for $\mathrm{CO}_{2}$ hydrogenation perceived by many authors including [Riedel et al., 1999] and [Jun et al., 2004]. The important reactions for FTS using $\mathrm{CO}-$ or $\mathrm{CO}_{2}$-rich syngas are as follows:

$$
\begin{aligned}
& \mathrm{CO}+2 \mathrm{H}_{2} \rightarrow-\mathrm{CH}_{2}-+\mathrm{H}_{2} \mathrm{O}+165 \mathrm{~kJ} / \mathrm{mol} \\
& \mathrm{CO}_{2}+3 \mathrm{H}_{2} \rightarrow-\mathrm{CH}_{2}-+2 \mathrm{H}_{2} \mathrm{O}+125 \mathrm{~kJ} / \mathrm{mol}
\end{aligned}
$$




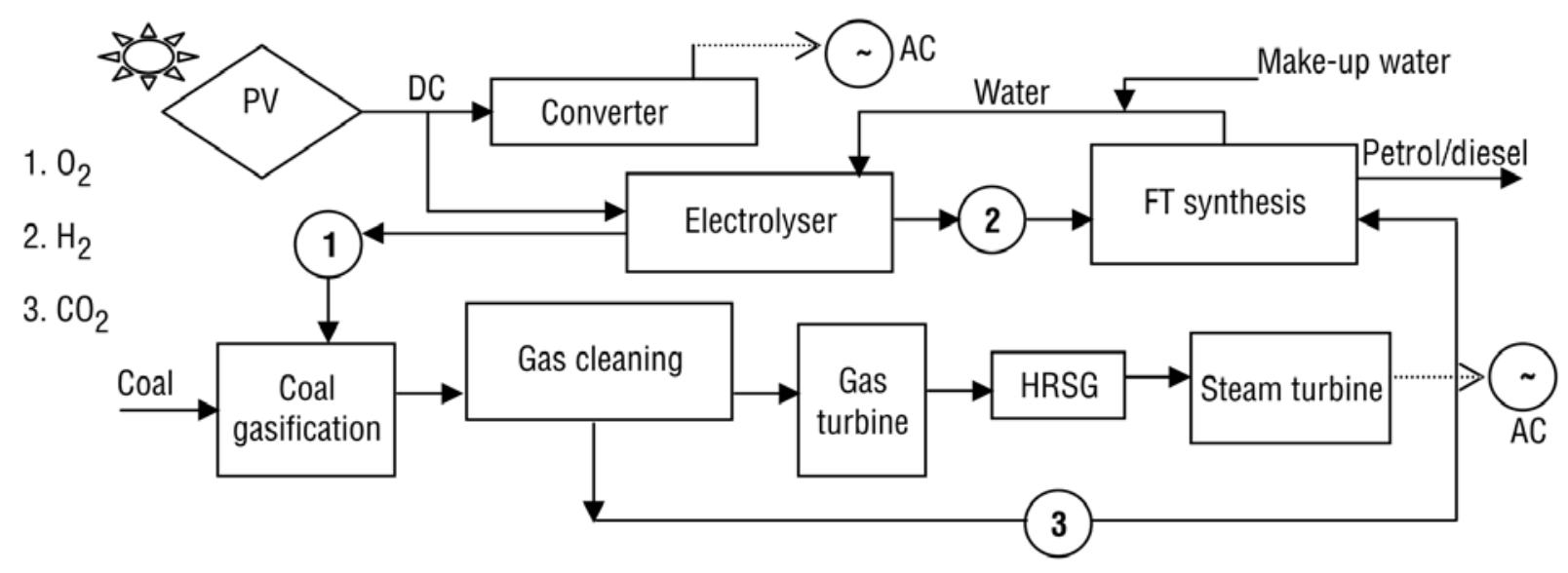

Figure 1. Integrated PV/IGCC plant with hydrocarbon liquid production [Gouse et al., 1993]

$\mathrm{H}_{2} \mathrm{O}+\mathrm{CO} \leftrightarrow \mathrm{CO}_{2}+\mathrm{H}_{2}$

(WGS and r-WGS reactions)

The reaction stoichiometry suggests a ratio of $\mathrm{H}_{2} / \mathrm{CO}$ equal to 2 , and $\mathrm{H}_{2} / \mathrm{CO}_{2}$ equal to 3 for a $\mathrm{H}_{2}$-balanced syngas - one in which $\mathrm{H}_{2}$ and $\mathrm{CO} / \mathrm{CO}_{2}$ requirement is met without the aid of the WGS reaction. The ratio of hydrogen to oxides of carbon would be between 2 and 3 in a mixed, $\mathrm{H}_{2}$-balanced syngas.

\subsection{Syngas from biomass}

Tijmensen et al. [2002] review the technical feasibility and economics of biomass integrated gasification-Fischer Tropsch (BIG-FT) process and also point out the key $\mathrm{R} \& \mathrm{D}$ issues involved in commercialization of this process. Boerrigter and den Uil [2002] give a similar review identifying a potential BIG-FT process configuration. Most of the literature on bio-syngas deals with the problems encountered in obtaining it. The main problem seems to be the gas-cleaning step involving the separation of tar and other volatiles like $\mathrm{NH}_{3}$ from the raw gas, for which different authors have compared the likely alternatives. This is necessary to avoid poisoning of the FTS catalyst. The literature dealing with actual conversion of bio-syngas to fuels using FTS is meagre. Jun et al. [2004] report experimental results of FTS done using a model bio-syngas. In his review on biofuels, Demirbas [2007] considers FT using bio-syngas as an emerging alternative.

The raw syngas from coal or biomass gasification is a mixture of $\mathrm{CO}, \mathrm{CO}_{2}, \mathrm{H}_{2}$ and $\mathrm{CH}_{4} . \mathrm{CH}_{4}$ is removed by reforming and conventional processes available separate $\mathrm{CO}_{2}$. Purified syngas with $\mathrm{CO}$ and $\mathrm{H}_{2}$ is fed to FT reactors. If $\mathrm{CO}_{2}$ is hydrogenated along with $\mathrm{CO}$ in the FT reactor, the expensive $\mathrm{CO}_{2}$ removal step may be eliminated.

2.3. Catalysts for $\mathrm{CO}_{2}$ hydrogenation

FT reactions are "sensitive", meaning that the catalyst composition, its properties and its method of manufacture decide the selectivity of the products obtained. The catalysts used for FTS are either cobalt or iron. Riedel et al. [1999] have studied the hydrogenation of $\mathrm{CO}_{2}$ over both these catalysts. In the absence of any WGS reaction promoter like $\mathrm{Mn}, \mathrm{CO}_{2}$ merely behaves as a diluting gas as it is neither strongly adsorbed nor hydrogenated on cobalt catalysts. When $\mathrm{Mn}$ is added to cobalt catalysts, reverse WGS is possible. FT chain growth on Co occurs due to strongly adsorbed $\mathrm{CO}$ on the surface. With a low partial pressure of $\mathrm{CO}$, these inhibitions are removed and the regime moves from $\mathrm{FT}$ process to methanation, yielding more of $\mathrm{CH}_{4}$. It was observed that even when the r-WGS reaction was fast, the attainable $\mathrm{CO}$ concentration was not sufficient to attain a FT regime. It was hence concluded that $\mathrm{CO}_{2}$ hydrogenation is not possible even on hybrid cobalt catalyst containing a shift catalyst like Mn.

Iron is the catalyst most widely used by SASOL in its reactors [Dry, 2002]. The low-temperature (LTFT) reactors, either multi-tubular fixed bed reactor (MTFBR) or slurry reactor (SR), operating at $\sim 25$ bar $\left(1\right.$ bar $=10^{5} \mathrm{~Pa}$, approximately atmospheric pressure) and $220-250^{\circ} \mathrm{C}$, use a precipitated iron catalyst. The high-temperature (HTFT) fluidized bed reactors, either fixed (SAS: Sasol advanced synthol) or circulating (synthol) operating at $\sim 25$ bar and $300-320^{\circ} \mathrm{C}$, use a fused iron catalyst. (Synthol is the name given to the HTFT reactors.) While the LTFT gives selectivity towards wax (and later, diesel on further treatment), the HTFT yields more of olefins, enabling the maximization of petrol yields. Iron is not only cheap but also possesses WGS activity, thereby giving FT reactors the flexibility to handle any type of syngas in terms of $\mathrm{CO}$ and $\mathrm{H}_{2}$. In their experiments with iron for $\mathrm{CO}_{2}$ hydrogenation, Riedel et al. [1999] found that alumina was the best support and potassium acted as a powerful promoter. $\mathrm{Cu}$ was added to the catalyst to enable easy reduction. They report that the hydrocarbon distribution from the $\mathrm{H}_{2} / \mathrm{CO}_{2}$ and $\mathrm{H}_{2} / \mathrm{CO}$ syngas is the same, but the reaction rate for $\mathrm{CO}_{2}$ syngas was about $43 \%$ lower than for CO-rich syngas. With the conventional silica support used, it is reported that $\mathrm{CO}_{2}$ oxidizes the catalyst and the activity for $\mathrm{CO}_{2}$ hydrogenation is low. Similar results are reported by Jun et al. [2004]. Schulz et al. [1999] have concluded through their studies that FT with $\mathrm{H}_{2} / \mathrm{CO}$ and $\mathrm{H}_{2} / \mathrm{CO}_{2}$ gave the same product composition at steady state, but the transient episodes existed for a longer time with the $\mathrm{CO}_{2}$-rich syngas. "Transient episodes" refers to 
the time when the catalyst is still undergoing changes (in terms of getting carbided and the subsequent phase changes) and the product slate is also varying. Once the catalyst reaches steady state, the product distribution remains constant. They also report no deactivation with the $\mathrm{CO}_{2}$-rich syngas. This was attributed to the low carbon formation tendency, as CO partial pressure is low owing to the WGS equilibrium constraints.

\subsection{Selectivity and yield}

The product selectivity and yields from an FT plant are vital to make the process viable economically. This depends on the catalyst used, reactor type, pressure, temperature and syngas conditions. Kim et al. [2006] compared the performance of the 3 main types of reactors, fixed bed, fluidized bed and slurry, for $\mathrm{CO}_{2}$ hydrogenation using Fe catalyst. Similar to CO hydrogenation, they report that light olefins and heavy hydrocarbons were respectively formed in the fluidized bed (HTFT) and slurry reactors (LTFT). A common feature found in the literature for FTS using $\mathrm{CO}_{2}$ is that the experiments used to report data were performed at $573 \mathrm{~K}$ and 10 bar using a $\mathrm{H}_{2} / \mathrm{CO}_{2}$ ratio of 3. Jun et al. [2004], who have used a model biosyngas, however, report data for both a $\mathrm{H}_{2}$-deficient and balanced feed at $573 \mathrm{~K}$ and 10 bar. Selectivity can also be predicted using kinetic models for product distribution, which are few in the literature. This was not observed in any of the literature studied for $\mathrm{CO}_{2}$ hydrogenation. We have simulated one of the existing kinetic models in the literature to study the effects of $\mathrm{CO}_{2}$ present along with the feed on the FT product selectivity, with emphasis on the WGS reaction considering an iron catalyst.

\section{Simulation studies and results}

\subsection{Reaction conditions}

In the case of $\mathrm{CO}_{2}$ hydrogenation, the equilibrium of the $\mathrm{CO}$ shift reaction is vital as it limits the maximum extent to which $\mathrm{CO}$ or $\mathrm{CO}_{2}$ can be converted in a mixture of $\mathrm{CO}, \mathrm{CO}_{2}, \mathrm{H}_{2}$ and $\mathrm{H}_{2} \mathrm{O}$. It is reported in the literature that the WGS reaction is in equilibrium under FT conditions, while FT reactions are all kinetically controlled. As mentioned earlier, for FTS using $\mathrm{CO}_{2}$, it has to be first converted to $\mathrm{CO}$ and $\mathrm{H}_{2} \mathrm{O}$ through the r-WGS reaction. The $\mathrm{CO}$ thus formed is consumed in the monomer formation for FT polymerisation. While r-WGS is endothermic, FT monomer formation and WGS are exothermic reactions. Overall, this gives $\mathrm{CO}_{2}$ hydrogenation an exothermic nature. But the lower exothermicity compared to CO hydrogenation makes the temperature control of the reactor easier [Riedel et al., 1999]. The main and deciding point is the additional demand for $\mathrm{H}_{2}$, which has to be met when using $\mathrm{CO}_{2}$-rich syngas. In the FT process, an increase in temperature thermodynamically favours methane formation and the selectivity moves towards $\mathrm{CH}_{4}$. On the other hand, r-WGS, being endothermic in nature, is favoured at high temperatures. Besides, the water formed from the r-WGS is strongly inhibiting on iron catalysts [Schulz et al., 1994] and limits the syngas conversion per pass. Riedel et al. [1999] suggested the use of different reactor volumes with optimized conditions for the two reactions.
Considering the r-WGS reaction alone gives the following options to increase conversion of $\mathrm{CO}_{2}$ to $\mathrm{CO}$ : removal of water formed, removal of $\mathrm{CO}$ or addition of $\mathrm{H}_{2}$. $\mathrm{CO}$ removal is dictated by FT reactions, and increasing the temperature, which gives undesired methane, can increase this rate. Meeting additional $\mathrm{H}_{2}$ demand is difficult and may again lead to more $\mathrm{CH}_{4}$ in the product. The remaining choice of water removal seems possible and was investigated in this work through simulations, while proposing a flow sheet for it. A fixed-bed reactor model was considered for performing the simulation studies. The kinetic model predicting the product distribution is taken from [Wang et al., 2003], for an industrial Fe-Cu-K catalyst. It also includes the WGS kinetics in it. The results of the simulations for a $\mathrm{H}_{2} / \mathrm{CO}$ syngas at different pressure, temperature, feed ratio and flow rate conditions were verified to be concurrent with the conclusions reached in the literature, like increase of $\mathrm{CH}_{4}$ selectivity with increase in temperature and $\mathrm{H}_{2} / \mathrm{CO}$ ratio and drop in conversion with increase in flow rate. The kinetic parameters reported in Wang's model were obtained for temperatures of 493$543 \mathrm{~K}$, pressures of $11-31$ bar and feed ratio of $\mathrm{H}_{2} / \mathrm{CO}$ from 0.98 to 2.99. Since $\mathrm{CO}_{2}$ formation is present in $\mathrm{FT}$ using CO-rich syngas, the model should predict the presence of $\mathrm{CO}_{2}$ in feed gas as well.

Simulations were performed with a single reactor for two cases of hydrogen concentration, one with a fixed concentration and the other a balanced concentration, while varying the ratio of $\mathrm{R}=\mathrm{CO}_{2} /\left(\mathrm{CO}+\mathrm{CO}_{2}\right)$ between $\sim 0$ and 1. For the balanced $\mathrm{H}_{2}$ case, the ratio $\mathrm{A}=\mathrm{H}_{2} /\left(2 \mathrm{CO}+3 \mathrm{CO}_{2}\right)$ equals 1 . The conditions used were 25-55 bar, 493-573 K, feed flow rate of $500 \mathrm{ml} / \mathrm{min}$ and $82 \mathrm{~g}$ of catalyst with a maximum carbon number of 50 in the product. The pressure (25 bar) and temperature (493 $\mathrm{K}$ and $573 \mathrm{~K}$ ) used in these simulations are representative of the LTFT and HTFT process respectively. As $\mathrm{R}$ approached 1, FT, syngas and hydrogen conversions monotonically decreased, methane selectivity and water content in the exit stream monotonically increased, and $\mathrm{CO}$ and $\mathrm{CO}_{2}$ conversions showed a change in sign (Figure 2 ). The reactors in the proposed process (Figure 3) should be operated in the range of $\mathrm{R}$ where $\mathrm{CO}_{2}$ conversion is positive, e.g., $\mathrm{R}>0.72$ at $493 \mathrm{~K}$ and 25 bar (Figure 2). Also, as R further increases to 1 , CO formation is observed, i.e., negative conversion of CO ( $R>0.90$ at $493 \mathrm{~K}$ and 25 bar). In this region, water removal would help not only the r-WGS to increase $\mathrm{CO}_{2}$ conversion, but also help $\mathrm{CO}$ conversion by reducing the possible inhibition effects of water. At a constant pressure, as the temperature increases, the feasible region for $\mathrm{R}$ values with positive conversion of $\mathrm{CO}_{2}$ expands (from 0.72 to 0.55 in Figure 2a). This would be expected, as at higher temperatures, r-WGS equilibrium conversion would increase. For a fixed temperature, as the pressure increases, there is not much change in the feasible range of $\mathrm{R}$ (Figure 2b), possibly because WGS, being an equimolar reaction, is not much influenced by change in pressure. The figures illustrated are for the case when A varied from 1.49 to 1 , as $\mathrm{R}$ varied from $\sim 0$ to 1 . Even when A equals 1 for varying $\mathrm{R}$, not 


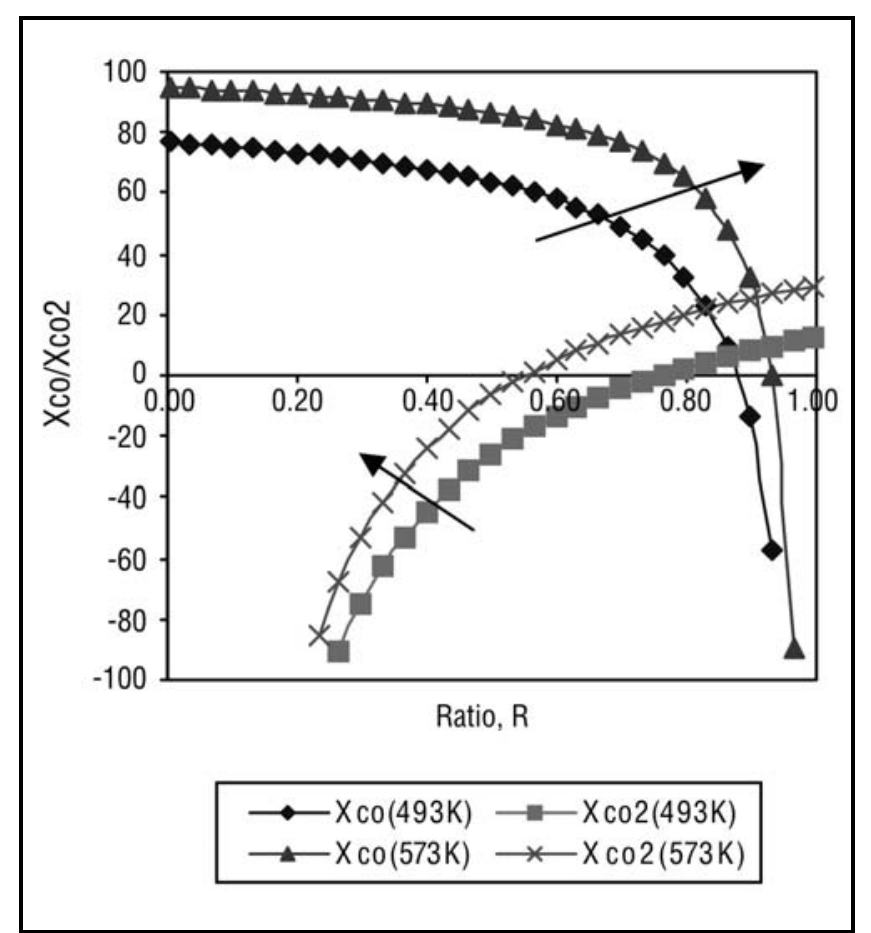

Figure 2a. $\mathrm{CO}$ and $\mathrm{CO}_{2}$ conversion at 25 bar

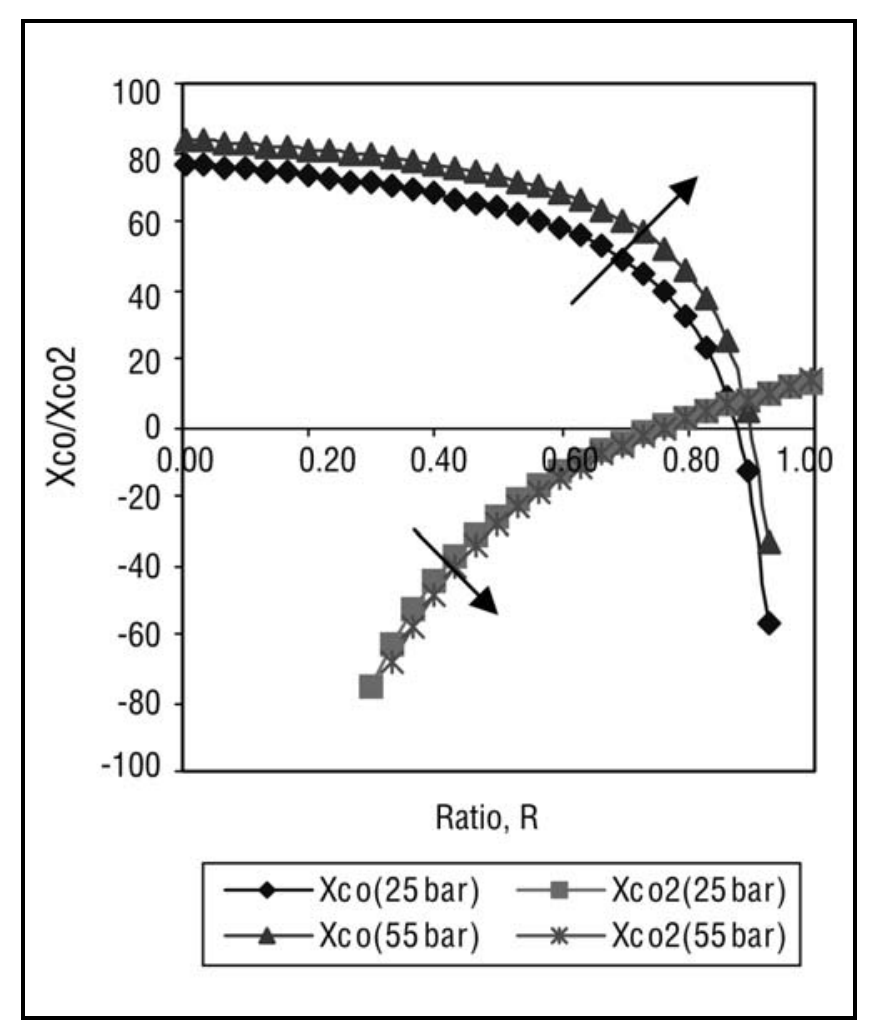

Figure $2 \mathrm{~b} . \mathrm{CO}$ and $\mathrm{CO}_{2}$ conversion at $493 \mathrm{~K}$

much change was observed in Figure 2. The arrows indicate the direction of increasing pressure or temperature in Figure 2.

In the region of $\mathrm{R}$ where $\mathrm{CO}_{2}$ is formed, i.e., for negative conversions of $\mathrm{CO}_{2}$, (e.g., $\mathrm{R}<0.55$ at 25 bar and $573 \mathrm{~K}$ ), it is proposed that a shift reactor (with r-WGS) alone would be first used to convert the $\mathrm{CO}_{2}$ in feed to
$\mathrm{CO}$ at relatively high temperatures ( $\sim 673 \mathrm{~K})$. The product then obtained would be subjected to the HTFT process. This is because of the conflicting requirements of pressure and temperature by the r-WGS and FT reactions, and hence both cannot be conducted in a single step. Joo et al. [1999] evaluated a similar process for methanol production. For the example considered in the next section (Section 3.2), we have performed simulations at $\mathrm{R}=0.91$, which satisfies the condition of $\mathrm{R}>0.72$ at 55 bar and $493 \mathrm{~K}$. For any temperature between the two extremes (of $493 \mathrm{~K}$ and $573 \mathrm{~K}$ ) at the same pressure (25 bar), the results lie within the region depicted in Figure 2.

At the chosen value of ratios for A and $\mathrm{R}$ in the paper, Figure 2 was generated with the help of simulations. Similar study can be done for different values of A. It is difficult to have a unique conclusion from the results shown owing to the variation in conversion if A is changed, and the example presented is an illustrative one. We have chosen a region that can be a potential candidate and carried out the simulation study.

\subsection{Performance of the proposed flow sheet}

To further improve $\mathrm{CO}_{2}$ conversion in the feasible region of $\mathrm{R}$ where $\mathrm{CO}_{2}$ conversion is positive, (e.g., $\mathrm{R}>0.55$ at 25 bar and $573 \mathrm{~K}$ ), the flow sheet in Figure 3 is proposed with an intermediate water removal step between the two FT reactors. The flow sheet consists of FT reactors (FT), separators (S) to separate the condensed water (and hydrocarbon, if any) and heat exchangers $(\mathrm{H})$. Feed having $\mathrm{CO}_{2}$ is preheated in $\mathrm{H} 1$ and enters the reactor FT-1. The exit streams from the reactors are cooled down in heat exchangers, so that water gets condensed. The water is removed in separators (S) and the exit gas from here is heated back to the reaction temperature and sent back to another FT reactor. The sequence continues till the required conversion for $\mathrm{CO}_{2}$ is achieved for a given volume of syngas feed and molar content of $\mathrm{CO}_{2}$ present in it.

Simulations for this flow sheet were performed using MATLAB for the reactor model and DESIGN-II for the heat exchanger and separator (flash) calculations. The inputs to the reactor model were: $\mathrm{P}=55 \mathrm{bar}, \mathrm{T}=493 \mathrm{~K}$, feed flow rate $=100 \mathrm{ml} / \mathrm{min}, \mathrm{H}_{2} / \mathrm{CO}=30, \mathrm{CO}_{2} / \mathrm{CO}=10$ and a catalyst weight of $200 \mathrm{~g}$ in each of the reactors. The maximum carbon number considered was 20 for simulations, to keep the calculations easier. Care was taken to ensure that the heat exchangers in the process did not have a temperature crossover, and had enough approach when the simulations converged.

The simulation exercise was performed for a set of 3 reactors, and compared with the simulated performance of a stand-alone reactor with $600 \mathrm{~g}$ of catalyst using the same conditions. The simulation results are given in Tables 1 and 2, and the following conclusions/comments were arrived at from the simulations performed.

1. The conversion of $\mathrm{CO}_{2}$ and syngas and the methane selectivity at exit of each reactor are nearly the same.

2. When compared with a single reactor, reactors in series showed better utilization of $\mathrm{H}_{2}$ and $\mathrm{CO}_{2}$ as seen from the conversion values. CO conversion and methane selectivity are similar in the two cases. 


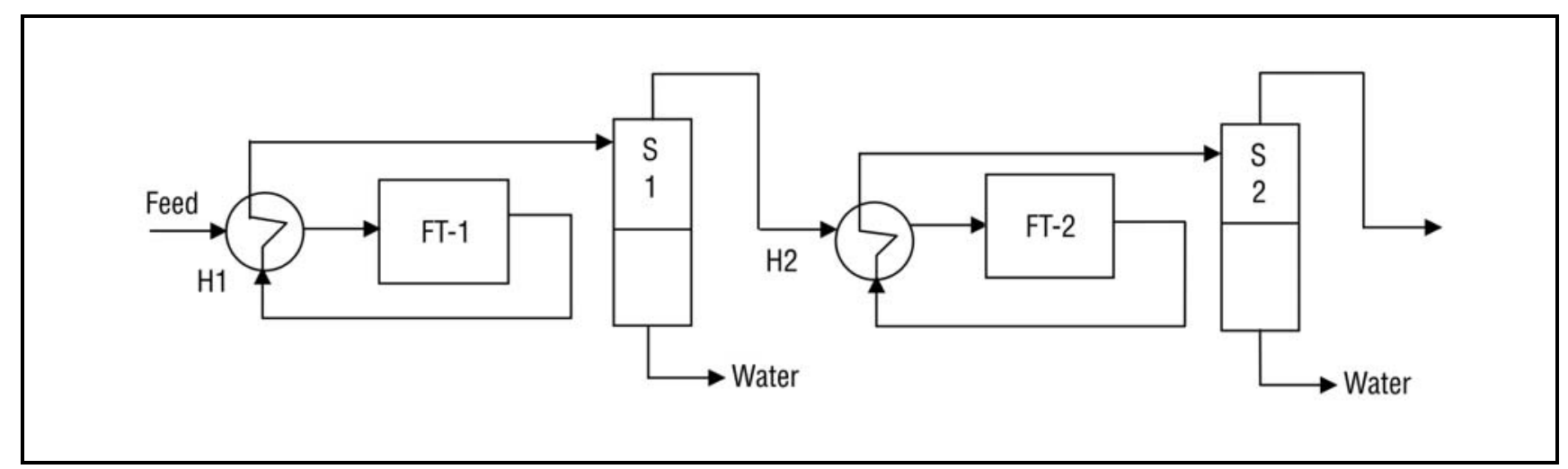

Figure 3. Proposed flow sheet for improved $\mathrm{CO}_{2}$ conversion in FTS

Table 1. Performance comparison of proposed flow sheet with a single FT reactor ${ }^{[1]}$

\begin{tabular}{|l|c|c|c|c|c|}
\hline \multirow{2}{*}{} & \multicolumn{3}{|c|}{ Molar flow at exit (mol/sec) } & \multicolumn{2}{c|}{ Exit conversion (\%) } \\
\cline { 2 - 6 } & Feed & Reactor 3 & Single reactor & Reactor 3 & Single reactor \\
\hline $\mathrm{CO}$ & $5.45 \mathrm{E}-05$ & $6.80 \mathrm{E}-06$ & $5.89 \mathrm{E}-06$ & 87.54 & 89.20 \\
\hline $\mathrm{H}_{2}$ & $1.64 \mathrm{E}-03$ & $5.93 \mathrm{E}-04$ & $9.03 \mathrm{E}-04$ & 63.74 & 44.80 \\
\hline $\mathrm{CO}_{2}$ & $5.45 \mathrm{E}-04$ & $2.92 \mathrm{E}-04$ & $3.78 \mathrm{E}-04$ & 46.47 & 30.76 \\
\hline $\mathrm{H}_{2} \mathrm{O}$ & 0 & $1.68 \mathrm{E}-04$ & $3.84 \mathrm{E}-04$ & - & - \\
\hline $\mathrm{CH}_{4}$ & 0 & $1.49 \mathrm{E}-04$ & $1.16 \mathrm{E}-04$ & - & - \\
\hline $\mathrm{CH}_{4}$ sel. & - & 79.93 & 83.43 & 79.93 & 83.43 \\
\hline
\end{tabular}

Note

1. $\mathrm{CH}_{4}$ selectivity is mole \% hydrocarbon in exit stream.

Table 2. Performance of each FT reactor in the proposed flow sheet ${ }^{[1]}$

\begin{tabular}{|c|c|c|c|c|c|c|}
\hline & Reactor 1 & Reactor 1 & Reactor 2 & Reactor 2 & Reactor 3 & Reactor 3 \\
\hline & In & Exit & In & Exit & In & Exit \\
\hline $\mathrm{CO}$ & 2.41 & 0.67 & 0.78 & 0.60 & 0.69 & 0.55 \\
\hline $\mathrm{H}_{2}$ & 73.20 & 59.65 & 68.40 & 53.91 & 61.89 & 47.59 \\
\hline $\mathrm{CO}_{2}$ & 24.39 & 22.54 & 25.85 & 22.85 & 26.23 & 23.43 \\
\hline $\mathrm{H}_{2} \mathrm{O}$ & 0.00 & 13.12 & 0.74 & 13.89 & 1.14 & 13.48 \\
\hline $\mathrm{CH}_{4}$ & 0.00 & 3.03 & 3.47 & 7.05 & 8.10 & 11.95 \\
\hline $\mathrm{C}_{2}$ & 0.00 & 0.34 & 0.39 & 0.72 & 0.83 & 1.22 \\
\hline $\mathrm{C}_{3}$ & 0.00 & 0.17 & 0.19 & 0.40 & 0.46 & 0.71 \\
\hline $\mathrm{C}_{4}$ & 0.00 & 0.08 & 0.09 & 0.28 & 0.32 & 0.50 \\
\hline $\mathrm{C}_{5}$ & 0.00 & 0.04 & 0.05 & 0.16 & 0.18 & 0.30 \\
\hline $\mathrm{C}_{6}$ & 0.00 & 0.02 & 0.02 & 0.08 & 0.09 & 0.17 \\
\hline $\mathrm{C}_{7}$ & 0.00 & 0.02 & 0.02 & 0.06 & 0.07 & 0.10 \\
\hline Xсо2 (\%) & - & 19.60 & - & 21.82 & - & 20.35 \\
\hline $\mathrm{Xft}(\%)$ & - & 24.72 & - & 22.18 & - & 20.59 \\
\hline Xsyngas (\%) & - & 30.58 & - & 30.33 & - & 31.39 \\
\hline $\mathrm{CH}_{4}$ sel. (mole \%) & - & 81.90 & - & 80.57 & - & 79.93 \\
\hline Vol. in $\mathrm{ml} / \mathrm{min}$ & 100 & 87.02 & 76.58 & 67.73 & 62.5 & 55.74 \\
\hline
\end{tabular}

Note

1. Compositions of components are in mole $\%$ 
3. The FT reactor operating temperature limited the temperature rise that can be achieved in the heat exchangers, and set an upper limit on them.

4. While doing the simulations, water and steam were used as utilities in the heat exchangers to ease calculations (and the primary aim was to see the effect of removal of water on $\mathrm{CO}_{2}$ conversion). The heat integration proposed in the flow sheet can be studied by setting up a better model in ASPEN, etc.

5. In contrast to values published for $\mathrm{CH}_{4}$ selectivity in the $\mathrm{CO}_{2}$ hydrogenation [Jun et al., 2004] experiments, the simulation results show $80 \%$ methane selectivity. This could be because of the kinetics considered, which was on a Fe-Cu-K catalyst, while most of the reported data is from experiments on a $\mathrm{Fe}-\mathrm{Al}_{2} \mathrm{O}_{3}-\mathrm{Cu}-\mathrm{K}$ catalyst. (The error probably lies in the activation energy for $\mathrm{CH}_{4}$ used, and its value over a Fe-Al catalyst should be used to verify the simulations. Changing the chain-growth parameter value for methane did not have considerable effects on the $\mathrm{CH}_{4}$ selectivity.) The higher methane selectivity may also be due to the high ratio of $\mathrm{H}_{2} / \mathrm{CO}$ used in the simulations. The catalyst promoter effects on conversion of $\mathrm{CO}_{2}$ and product selectivity for a Fe-Cu catalyst are reported by Yan et al. [2000]. A comparison of the reaction in slurry and fixed bed reactors is also included in their study.

\section{Conclusions}

Biomass offers the choice of producing liquid, carbonneutral transportation fuels using FTS. Since bio-syngas contains good amounts of $\mathrm{CO}_{2}$, technologies for $\mathrm{CO}_{2}$ hydrogenation using FTS are needed. For a $\mathrm{CO}_{2}$-rich syngas, the proposed flow sheet having multiple FT reactors in series with intermediate water removal gave a better $\mathrm{CO}_{2}$ conversion compared to a single reactor. More detailed simulations of this with a more reliable kinetic model and a preliminary economic analysis are necessary to evaluate its commercial potential. A “conventional” FT conversion system works with a recycle of unconverted syngas to enhance the conversion and is not considered in this work.
Nevertheless, under a once-through conversion process, the proposed flow sheet performs better than a single reactor system. Whether a higher or lower $\mathrm{CO}_{2}$ concentration in feed gas is good for FT liquid production would depend on both the $\mathrm{H}_{2}$ balance and $\mathrm{CO}$ present in the feed. The analysis method illustrated in this paper can help to decide if one should have a single reactor or a reactorsin-series system. The conventional FT processes remove any $\mathrm{CO}_{2}$ in the feed gas and take a feed of $\mathrm{CO}$ and $\mathrm{H}_{2}$ only. So, one cannot really compare the option of using higher $\mathrm{CO}_{2}$ concentration syngas with the conventional FT system.

\section{References}

Boerrigter, H., and den Uil, H., 2002. "Green diesel from biomass via FTS: new insights in gas cleaning and process design", Pyrolysis and Gasification of Biomass and Waste, Expert Meeting, Strasbourg, France, 30 September-1 October.

Demirbas, A., 2007. "Progress and recent trends in biofuels", Progress in Energy and Combsn. Sci., 33(1), pp. 1-18.

Dry, M.E., 2002. "Fischer-Tropsch Process: 1950-2000", Cat. Today, 71, pp. 227-241.

Gouse, S.W., Gray, D., and Tomlinson, G., 1993. "Integration of fossil and renewable energy technologies to mitigate carbon dioxide", Energy Convers. Mgmt., 34, pp. 1023-1030.

Joo, O.S., Jung, K.D., Moon, I., Rozovskii, A., Lin, G.I., Han, S.H., and Uhm, S.J., 1999. " $\mathrm{CO}_{2}$ hydrogenation via a r-WGS reaction", Ind. Eng. Chem. Res., 38, pp. 1808-1812.

Jun, K.W., Roh, H.S., Kim, K.S., Ryu, J.S., and Lee, K.W., 2004. "Catalytic investigation of FTS from biomass derived syngas", App. Cat. A, 259, pp. 221-226.

Kim, J.S., Lee, S., Lee, S.B., Choi, M.J., and Lee, K.W., 2006. "Performance of catalytic reactors for the hydrogenation of $\mathrm{CO}_{2}$ to hydrocarbons", Cat. Today, 115, pp. 228-234.

Rao, V.U.S., Stiegel, G.J., Cinquegrane, G.J., and Srivastava, R.D., 1992. "Iron-based catalysts for slurry phase FTS: technology review", Fuel Proc. Tech., 30, pp. 83-107.

Riedel, T., Claeys, M., Schulz, H., Schaub, G., Nam, S.S., Jun, K.W., Choi, M.J., Kishan, G., and Lee, K.W., 1999. "Comparative study of FTS with $\mathrm{H}_{2} / \mathrm{CO}$ and $\mathrm{H}_{2} / \mathrm{CO}_{2}$ syngas using Fe and Co catalysts", App. Cat. A, 186, pp. 201-213.

Schulz, H., van Steen, M., and Claeys, M., 1994. "Selectivity and mechanism of FischerTropsch synthesis with iron and cobalt catalysts", Stud. Surf. Sci. Catal., 81, pp. 455-460. Schulz, H., Schaub, G., Claeys, M., and Riedel, T., 1999. "Transient initial kinetic regimes of Fischer-Tropsch synthesis", App. Cat. A, 186, pp. 215-227.

Tijmensen, M.J.A., Faaij, A.P.C., Hamelinck, C.N., and van Hardeveld, M.R.M., 2002. "Exploration of the possibilities for production of FT liquids and power via biomass gasification", Biomass and Bioenergy, 23, pp. 129-152.

Wang, Y.N., Ma, W.P., Lu, Y.J., Yang, J., Xu, Y.Y., Xiang, H.W., Li, Y.W., Zhao, Y.L., and Zhang, B.J., 2003. "Kinetics modelling of Fischer-Tropsch synthesis over an industrial FeCu-K catalyst”, Fuel, 82(2), pp. 195-213.

Yan, S.R., Jun, K.W., Hong, J.S., Choi, M.J., and Lee, K.W., 2000. "Promotion effect of $\mathrm{Fe}-\mathrm{Cu}$ catalyst for the hydrogenation of $\mathrm{CO}_{2}$ and application to slurry reactor", App. Cat. A, 194-195, pp. 63-70.

\section{Energy for Sustainable Development and its role in IEl's mission}

IEI's journal Energy for Sustainable Development (ESD) is meant to be a vehicle of communication between Northern and Southern energy actors on the energy goals and policies as well as energy plans and projects in developing countries. It also aims to promote South-South interactions to tackle these problems.

ESD attempts to provide a balanced treatment of:

- renewables and end-use efficiency (in the industrial, transport, domestic, commercial and agricultural sectors);

- generation (including development) of energy technologies and their dissemination;

- hardware (for the conversion of primary energy as found in nature into convenient secondary energy, for transmission/transport and distribution and for utilisation in end-use devices); and

- software (relating to energy policies, institutions, management and financing).

Articles and short articles published are subject to a formal process of anonymous peer review. 